\title{
O IMPACTO DO ABORTO ILEGAL NA SAÚDE REPRODUTIVA: SUGESTÕES PARA MELHORAR A QUALIDADE DO DADO BÁSICO E VIABILIZAR ESSA ANÁLISE
}

\author{
Rebeca de Souza e Silva*
}

Resumo: Estatísticas fidedignas sobre o aborto provocado, provenientes de paises em que essa prática é legalizada, permitem uma adequada avaliação do impacto do aborto na Saúde Reprodutiva. Paradoxalmente, é justamente nesses países que observam-se os menores danos à Saúde da Mulher enquanto que, mesmo pautando-se em dados pouco ou nada confiáveis, o custo da prática clandestina é altíssimo: suas sequelas são bastante frequentes e, não raras vezes, levam ao óbito. Avaliar-se o quão alto é este custo, contudo, é uma tarefa bastante árdua e, infelizmente, dependendo do enfoque desejado pode até ser inexequivel. A solução mais acertada para a resolução desse dilema seria, a julgar pela literatura especializada, legalizar-se o aborto. Nessa eventualidade, além de se reduzir, automaticamente, os custos da prática clandestina, a análise do dueto Aborto/ Saúde, por si, permitiria remover os custos remanecentes.Mas, enquanto se convive com uma legislação restritiva, a solução mais sensata, é buscar otimizar a qualidade de análise daquele dueto. Nesse sentido, pode-se recorrer à adoção de uma técnica estatística que remove o maior dos entraves na determinação da dinâmica do aborto ilegal - a saber, a sub-declaração e/ou sub-registro da frequência de recorrência ao aborto -, a TRA; bem como elaborar-se estudos populacionais, a partir de um plano de amostragem simplificado, sobretudo por serem rarissimos frente aos estudos baseados em dados hospitalares, apesar de fornecerem informações bem mais amplas sobre a dinâmica do aborto.

Palavras-chave: aborto ilegal, saúde reprodutiva, técnica de resposta ao azar e amostragem simplificada

* Professora Adjunta da Universidade Federal de São Paulo - UNIFESP. 


\section{O STATUS LEGAL DO ABORTO PROVOCADO NA AMERICA LATINA}

$\mathrm{Na}$ América Latina são poucos os paises que revisaram as severas leis implementadas no século passado, impedindo o aborto provocado. Consequentemente, ele ou é realizado clandestinamente em clínicas particulares ou auto-provocado, via de regra em condições precárias. Em quatro paises, Colômbia, Haiti, Panamá e República Dominicana, o aborto é proibido em qualquer circunstância; noutros sete, Chile, Guatemala, Honduras, Jamaica, Nicarágua, Paraguai e Venezuela, somente é permitido quando a gravidez representa uma grave ameaça à vida da mãe. Brasil, Equador, México e Uruguai, também o permitem quando a mãe corre risco iminente de vida e nos casos de gravidez resultante de "violação"; nesses últimos, a morosidade burocrática acaba, para uma boa parcela de mulheres, inviabilizando a prática do aborto legal. Apenas em seis países vigora uma legislação pouco menos restritiva: Argentina, Bahamas, Barbados, Bolívia, Costa Rica e Perú, permitindo-se o aborto nos casos em que a gravidez simplesmente compromete a saúde física da mulher mesmo sem que a vida esteja sob risco. Em El Salvador se reconhece, além disso, a perspectiva de deformidade do feto - indicações eugenésicas - como justificação legal para o aborto (ISAACS \& SANSHUEGA, 1975; TIETZE, 1980; DAVID, 1974).

Em contrapartida, em Cuba, a única restrição de acesso ao aborto é a de que as mulheres solteiras com menos de 18 anos de idade necessitam do consentimento dos pais para realizá-lo. Ademais, o código penal vigente desde 1979 estabelece penas severas para o aborto ilegal, que é, por definição, o praticado com finalidade de lucro, feito fora do hospital ou sem o consentimento da mulher (HOLLERBACH, 1980).

\section{ABORTO PROVOCADO E SAÚDE REPRODUTIVA}

Desafortunadamente, não existem dados confiáveis para se avaliar a ocorrência do aborto provocado, especialmente a do clandestino - como se verá adiante, vários são os fatores que contribuem para justificar esta situação. Em decorrênicia, avaliar-se o peso 
do aborto provocado na morbi-mortalidade materna não é fácil. Contudo, há fortes indícios de que as complicações dele decorrentes são muito mais frequentes e costumam ser muito mais graves, até fatais, quando realizado por pessoal não qualificado do que quando realizado sob a responsabilidade de médicos, em lugares adequados.

Ademais dos obstáculos inerentes à obtenção da informação básica - entre os quais inclui-se a omissão deliberada da palavra "provocado" em prontuários médicos, visando evitar-se eventuais processos criminais -, a dificuldade em avaliar-se a morbidade materna reside, além disso, em não existir consenso a respeito dos "sintomas" ou "sinais" que devem ser considerados como complicações decorrentes da provocação do aborto. Os sinais preocupantes, em geral, referem-se a: perfuração do útero, considerado como sendo o mais perigoso por poder originar uma peritonite; lesões do colo do útero que embora menos graves, revelam-se bastante frequentes; esterilidade permanente ${ }^{1}$; alterações da capacidade uterina que, eventualmente, conduzem à esterilidade, gravidez ectópica, aborto espontâneo, parto prematuro, baixo peso ao nascer, ou ainda provocar complicações numa próxima gestação e/ou parto²; hemorragias, embolia pulmonar e/ou infarto (TIETZE \& LEWIT, 1972); e, finalmente, as sequelas psicológicas ${ }^{3}$.

Sobretudo em função da dificuldade em obter-se dados fidedignos, estudos sobre o papel que o aborto provocado desempenha na vida reprodutiva da mulher, são raros em nosso meio. Seu impacto na saúde reprodutiva ou materna é, na maior parte das vezes visto, simplesmente, sob a ótica da mortalidade, dada a precisão do conceito "óbito".

As estatisticas mais completas sobre mortalidade subsequente ao aborto legal provêm da Europa Oriental, da antiga Tchecoslováquia e da Hungria. Por isso, os dados

1. A respeito, veja-se CRAFT et al,1979: TIETZE et al, 1972

2. A respeito, veja-se HOGUE et al, 1982; OMS, 1979

3. A respeito, veja-se DAVID \& FRIEDMAN, 1973; WOLF, 1971: PACK \& MARCUS, 1966 
referentes a estes paises são utilizados frequentemente como parâmetros para se referendar a tendência ao declínio verificado na mortalidade materna por aborto a partir do momento de sua legalização.

Com efeito, no decênio de 1950, Tchecoslováquia e Hungria passaram a adotar uma legislação menos restritiva em termos de aborto. Num período de 4 anos subsequentes à implementação das leis - entre 1953 e 1957 e entre 1958 e 1962, respectivamente -, pôde-se observar um declínio de $56 \%$ e $63 \%$ nas taxas de mortalidade por este tipo de causa para os paises na ordem citada. Nenhum outro pais da Europa ou da América do Norte experimentou uma redução de tal magnitude durante os anos 50 e inicio dos 60 sem a descriminalização da prática do aborto provocado (HENSHAW et alii, 1982).

A partir do anterior, argumenta-se que a mortalidade por aborto só é elevada nos paises onde 0 aborto é ilegal, especialmente quando não são praticados por pessoas qualificadas. Esta argumentação tem sua razão de ser. Na América Latina, por exemplo, a literatura sobre o tema revela que, na maioria dos paises, o aborto provocado constituise em uma das principais causas de mortalidade materna, senão a principal.

Do exposto, conclui-se que uma legislação tolerante pode ser suficiente para minimizar significativamente os efeitos danosos que o aborto clandestino imprime à saúde reprodutiva das mulheres que recorrem a tal prática.

\section{ABORTO PROVOCADO E ANTICONCEPÇÃO}

Os motivos que levam uma mulher a provocar um aborto refletem, em geral, sua inserção no sistema de valores e costumes da sociedade em que vive. Por exemplo, na maioria das culturas modernas certas gravidezes são consideradas, do ponto de vista social, indesejáveis. Entre elas, cabe citar as que correspondem às mulheres solteiras, às resultantes de um estupro, incesto ou adultério, e às mulheres que já têm filhos adultos. 
Em última instância, contudo, o motivo fundamental que leva uma mulher ou casal a recorrer ao abortamento provocado está na necessidade de manter o número de filhos dentro dos limites econômicos considerados convenientes - este padrão é também socialmente constituido. Além disso, na maioria dos casos de gestações indesejadas, incidem as pressões psicológicas que tanto podem conduzir ao nascimento do filho indesejado - o que não raras vezes, pertuba o bem estar familiar -, como também podem, ao optar-se pela interrupção da gravidez, agravar o quadro de morbidade associado à prática. Ou seja, essa opção pode ser dramática e, paradoxalmente, a própria sociedade que condena a prática leva, quer pela valoração de famílias pequenas, quer pela incapacidade de manutenção de um contigente populacional elevado, à sua efetivação. Ademais, tanto em decorrência do pequeno leque de alternativas contraceptivas, como pela dificuldade de acesso às mesmas, o aborto provocado acaba sendo uma das únicas alternativas de se evitar um nascimento indesejado.

Assim sendo, tem sido sugerido que facilitando-se o acesso ao aborto provocado, as mulheres se veriam tentadas a substituir a anticoncepção pelo abortamento. Contudo, com base na experiência dos paises que adotaram legislação liberal de aborto, parece não haver evidências nesse sentido (MOORE-CAVAR, 1974; MOORE-CAVAR et al, 1976). Ao contrário, são os contraceptivos eficazes - pilula, DIU e esterilização - os que mais pesam no controle da fecundidade (VAN, 1974). Mais que isso, pôde-se observar que na antiga URSS, uma extensa campanha de difusão dos efeitos do aborto aliada à larga fabricação de diferentes dispositivos intra-uterinos, resultou na substituição do aborto legal por anticonceptivos (DAVID, 1980). De qualquer forma, deve ser levado em consideração que TIETZE $(1976,1979)$ comprovou, de forma conclusiva a utilização de métodos contraceptivos eficazes aliada ao aborto legal precoce como "apoio" - no caso de falhas do método ou de seu uso -, constituir-se no regime reversivel mais seguro para a regulação da fecundidade em qualquer idade. Uma vez mais, portanto, fica evidenciado que os efeitos nocivos do aborto provocado decorrem, essencialmente, da prática clandestina. 
Tanto para o Brasil, quanto para o Estado de São Paulo, a aplicação de um modelo de decomposição da fecundidade, elaborado por BOONGARTS (1980), permitiu destacar a importância dos métodos contraceptivos - na época, referindo-se quase exclusivamente à pílula - e do aborto provocado, sobretudo do primeiro, no acentuado declínio da fecundidade verificado no transcorrer da década de 70. (BERQUÓ \& MERRICK, 1983). No declínio de fecundidade ocorrido no Estado de São Paulo - que diga-se de passagem, foi bem mais intenso que o anotado no país -, também é aquele componente que desempenha papel decisivo, mas o aborto provocado desponta com importância bem mais acentuada. Aliás, acredita-se que este só não se apresente como o de m-" "destaque devido à alta subestimação desses eventos (BERQUÓ et alii, $1^{10 \circ}$

Ou seja, em grandes linhas, pode-se argumentar que o declínio da fecundidade ocorrido no Brasil, na década de 70, deveu-se ao largo uso da pilula e do aborto provocado. $\mathrm{Na}$ década de 80 lamentavelmente, esses métodos foram substituidos, em não pequena escala, pela esterelização feminina (A respeito c .. sulte-se, por exemplo, FSEADE 1994).

Condena-se a provocação do aborto, prática cirúrgica de baixíssimo risco quando realizada em condições adequadas, mas convive-se tranquilamente com uma maciça esterelização cirúrgica com risco, no mínimo, igual ao daquela, além disso, a esterelização é irreversivel. O que é pior, a esterelização não induz à redução do volume de abortos/ano, reduzindo, no limite, a média de abortos por mulher (SILVA, 1994).

Parece, portanto, que mulheres e/ou casais buscam livrar-se de uma gravidez indesejada a qualquer preço. Como nos dias de hoje o número de filhos desejados situase entre dois e três, além das relações sexuais pré-maritais serem cada dia mais frequentes, verifica-se um incremento no número de gravidezes indesejadas, sobretudo por parte das solteiras e unidas com pelo menos dois filhos. $O$ aborto provocado é o único meio de solucionar o impasse. Para evitar-se uma futura gravidez indesejada, às unidas cabe a opção pela esterelizaçăo mas, às solteiras apenas um outro aborto. (SILVA, 1992). 


\section{OBSTÁCULOS À AVALIAÇÃO DA OCORRÊNCIA DO ABORTO PROVOCADO}

A prática do aborto induzido, particularmente a clandestina, envolve uma complexa rede de aspectos políticos, sociais, culturais e psicológicos que acabam tanto por "condenar moralmente" os que a ela recorrem como também, o que não poderia deixar de ser, por leva-los a omitirem deliberadamente essa experiência. Assim sendo, o problema da subestimação da informação básica desponta, ao nosso ver, como o maior obstáculo a ser superado. Somam-se a esse os referentes à incongruência nas medidas, taxas e proporções, e à fonte de dados, o que torna árduo chegar-se a conclusões adequadas sobre a ocorrência do evento em pauta. Alguns dos principais entraves que permeiam a análise do aborto clandestino podem ser resumidos em:

\section{Sobre as medidas}

A frequência do aborto pode ser avaliada relacionando-a com população - quer seja a total, a feminina ou ainda a feminina em idade fértil (situada convencionalmente entre 15 e 44 anos ou entre 15 e 49 anos) - ou eventos gestacionais: quer seja o total de nascimentos, de partos ou gestações. Alguns autores anglo-saxônicos propuseram denominar-se taxa a relação abortos/população e proporção a relação abortos/eventos gestacionais (OMS, 1970). Desafortunadamente, entretanto, esta distinção não foi acatada universalmente.

Esses dois enfoques propiciam dados distintos embora, quando utilizados conjuntamente possibilitem situar adequadamente o problema do aborto. Ademais, dependendo do numerador ou denominador adotados, podem ser estabelecidas mais de cinquenta maneiras diferentes - quer por via de taxas quer por proporções - de medir-se o aborto, o que pode induzir a confusões, além de possibilitar a ocorrência de sérios erros de interpretação se não se observa o diferente valor que elas têm.

Por exemplo, a proporção de gestações que terminam em aborto. Esta não se presta a diagnosticar alterações na ocorrência do mesmo em determinada localidade 
porque, no periodo estudado, a população pode sofrer uma redução no número de casos gestacionais, em termos absolutos. Mas, como o número de abortos não decresce correlativamente - como ocorre nas populações que passam a adotar a prática da anticoncepção em forma eficaz -, pode-se observar um acréscimo na razão de abortos por gestações; com isso, via de regra, infere-se que a anticoncepção aumenta a incidência do aborto. Este é um erro que se comete com certa frequência (GASLONDE, 1973).

Porisso, Gaslonde alega que a relação abortos/mulheres em idade fértil, constituise na medida mais indicada para se avaliar as alterações na frequência do aborto provocado, tanto em uma mesma população, em dois momentos distintos de tempo, quanto entre duas populações, num mesmo período do tempo. Em contrapartida, na avaliação de comportamentos diferenciais do aborto provocado, a medida mais indicada é a proporção de abortos por gestações (REQUENA, 1966). Nossa experiência pessoal endossa tais indicações das medidas.

Percebe-se, pois, que a eleição de uma ou outra medida não se constitui em tarefa tão difícil, sendo ainda mais simples quando se adota o período de referência de um ano. Resta sensibilizar os pesquisadores da área para a importância de adotar-se uma medida universal.

\section{Sobre materiais e métodos}

Teoricamente, existem várias maneiras de se captar informações sobre o aborto provocado. Assim é que, não raras vezes, da leitura dos trabalhos sobre o tema extrai-se a idéia, falsa, de que poucas serão as dificuldades para proceder-se adequadamente à investigação do referido evento.

As estatisticas oficiais de abortos legais, obviamente, seriam o instrumento mais eficaz, constituindo-se no ponto de referência para validação de estimativas derivadas de outras fontes de dados. Não obstante, esta fonte não está livre de imperfeições. Segundo 
a OMS (1978), somente em alguns dos paises onde o aborto é legalizado dispõe-se de registros que oferecem informações fidedignas e completas de sua ocorrência. Provavelmente, a informação é mais completa quando, por lei, é obrigatório autorizar-se oficialmente cada aborto e quando todos os abortos legais são realizados em hospitais ou estabelecimentos sujeitos à fiscalização oficial e é menos completa para os abortos realizados em consultórios particulares. Nesse sentido, além de sub-informação, podem ocorrer imprecisões com respeito às caracteristicas pessoais da mulher, tais como local de residência, idade e duração da gestação, contaminadas pela ilegalidade do evento, valores pagos, relações matrimonais afetadas.

Nos países onde a legislação é restritiva a única possibilidade de se estudá-lo com as estatísticas oficiais é relacionando o aborto ao dano máximo: o óbito. Até onde se tem conhecimento, entretanto, a qualidade deste procedimento é bastante questionável. Realmente, em pesquisa realizada pela Organização Pan-Americana/OMS, em 11 cidades das Américas e uma da Inglaterra, no período 1962/64, a revisão realizada nos atestados de óbitos - mediante utilização de informação adicional -, teve por efeito aumentar os coeficientes de mortalidade materna por causas, particularmente por aborto, em quase todas as cidades onde a investigação se desenvolveu.

Além das imprecisões das informações contidas nos atestados de óbitos, outra desvantagem dos estudos por essa via é a de não se conseguir avaliar em que medida o aborto é realizado. Como o certificado da causa de morte costuma ser inexato e desconhecendo-se a taxa de letalidade de cada enfermidade, não é possivel extrair das estatísticas de mortalidade sequer uma estimação, ainda que aproximada, da incidência do aborto ilegal (OMS, 1978).

Não se deve perder de vista, entretanto, que se o objetivo do estudo limita-se ao conhecimento das causas de mortalidade por aborto, enfocando-se os óbitos por esta causa, junto com outros óbitos maternos e/ou com óbitos por outras causas em mulheres em idade reprodutiva, ficam minimizadas as imprecisões da fonte de dados em questão. 
Tal procedimento, portanto, pode ser bastante útil para determinar-se a influência que exerce a prática do aborto - legal ou ilegal - como causa de mortalidade materna.

Quanto aos dados colhidos em arquivos policiais, salienta-se que não oferecem uma informação válida sobre a ocorrência do fenômeno, pois mesmo nos paises onde o aborto é totalmente ilegal e a realização clandestina do mesmo é frequente, raramente isto dá lugar a processos de investigação policial.

As estatísticas hospitalares, por sua vez, somente propiciam informações sobre uma parte dos abortos que ocorrem em determinado lugar, posto que quando o mesmo cursa sem complicações, não ocorre hospitalização. Como as técnicas abortivas vêm se aperfeiçoando a cada dia, o número de casos de aborto provocado que requer hospitalização tem sofrido considerável redução. Consequentemente, tais estatísticas revelam-se, pelo menos, insuficientes para responderem às questões mais relevantes que envolvem 0 conhecimento do abortamento.

Segundo a OMS (1970), raras vezes é possivel calcular-se, com um grau razoável de exatidão, que porcentagem do total de abortos requer hospitalização, além de que, seguramente. esta varia dentre e entre regiões. Tudo leva a crer, contudo, que uma minuciosa pesquisa divulgada recentemente pelo Instituto Alan Guttmacher (1994) tenha obtido sucesso nessa tarefa. Mais precisamente, nela consegue-se estimar adequadamente o nivel global de ocorrência do aborto clandestino. Mas, possivelmente por inviabilidade operacional, não aborda os diferenciais de comportamento.

Segundo SANTEE (1975), as entrevistas domiciliares de caráter prospectivo constituem-se no instrumento mais eficaz para se avaliar, abrangentemente, a questão do aborto clandestino. Os niveis de ocorrência obtidos no levantamento prospectivo do PEAL/ TRANSLONG indicam, na visão daquele autor, que o enfoque prospectivo é mais eficiente que o retrospectivo para recolher informações sobre o aborto, possibilitando, inclusive, realizar-se uma análise mais discriminada de sua ocorrência. 
A experiência ensina, contudo, que não é fácil obter a cooperação das entrevistadas, a ponto de muitas se auto-excluirem do estudo. Além disso, outro aspecto negativo é de serem demasiadamente caros, sobretudo quando requerem a prática de provas laboratoriais (OMS, 1978).

Por fim, dentre as possibilidades que se apresentam para avaliar o abortamento ilegal, o levantamento retrospectivo sobra como a melhor alternativa. Este levantamento permite calcular, com bastante precisão, a variação da incidência do fenômeno ao longo do tempo, bem como obter dados sobre determinadas características das mulheres que se dispöem a declarar a provocação de um aborto.

É óbvio que esta modalidade de avaliação também não é isenta de críticas. Permeia-se por problemas de subestimação, não só em função das dificuldades em abordar o tema - decorrentes dos variados aspectos legais, culturais e religiosos -, que seguramente conduzem a omissões voluntárias de informações, como também por problemas decorrentes do fator memória, que conduzem a omissões involuntárias.

Além disso, este levantamento encontra-se sujeito a erros sistemáticos, que variam segundo as características concretas das informantes. Nesse sentido, existem evidências de que o levantamento retrospectivo permeia-se de sub-informação, mesmo quando o foco de interesse da pesquisa reside em abordar o aborto provocado legalmente. Com efeito, na Hungria (1977), ao se realizar este tipo de levantamento, dois anos após a liberação do aborto, captou-se somente $55 \%$ de casos. Omissão dessa mesma ordem foi detectada posteriormente nos Estados Unidos (SINGH \& WULF, 1991).

$\mathrm{Na}$ tentativa de melhorar a qualidade da informação retrospectiva, vários pesquisadores da América Latina utilizaram-se de uma metodologia especial para captar o aborto provocado. Sob a alegação de que as mulheres têm muita resistência em declarar a indução de um aborto e de que muitas vezes elas reportam como espontâneos os abortos que na realidade săo provocados, tal metodologia recomenda perguntar-se sobre 
a perda - englobando os abortos espontâneos e os provocados ilegalmente -, posto ter esta uma conotação de inevitável, para a qual não existe reprovação alguma. Ao que tudo indica, contudo, este esforço adicional realizado na tentativa de melhorar a qualidade da informação retrospectiva revelou-se antiproducente, sobretudo por inviabilizar, justamente, a caracterização do evento clandestino.

Outro é o caso da Técnica de Resposta ao Azar (TRA), que possibilita melhorar a estimação do aborto ilegal, em função de permitir à entrevistada dar informações sobre temas sumamente delicados, sem contudo revelá-los ao entrevistador.

Estimativas derivadas do emprego desta técnica foram comparadas com as obtidas via técnica retrospectiva convencional em Taiwan (CHI et alii, 1972), Canadá (KROTKI \& MC DANIEL, 1977), Etiópia (CHOW, 1979) e Turquia (TEZCAN \& OMRAN, 1981) revelandose sistematicamente mais altas. Além disso, RIDER et alii (1976) notaram que as estimativas obtidas por via desta técnica năo diferiam, estatisticamente, das obtidas via levantamento prospectivo, sendo que estas superavam em quase $100 \%$ as estimativas derivadas do levantamento retrospectivo convencional.

\section{TÉCNICA DE RESPOSTA AO AZAR (TRA)}

O grau de recusa notado em abordagem direta encontra-se estritamente relacionado com o caráter da questão formulada; assim é que as perguntas inócuas tendem a receber boas respostas, ao passo que as "polêmicas" - por vergonha, medo ou desconfiança tendem a ser mascaradas. Assim, se o alvo da pesquisa é o aborto clandestino na qual, necessariamente, a resposta é "comprometedora", ao proceder-se o levantamento da informação nos moldes convencionais - abordagem direta -, constata-se um altissimo grau de omissão.

Com o intuito de solucionar esse impasse, ou mais rigorosamente, com o objetivo de reduzir ou até mesmo eliminar essas omissões, WARNER (1965) propôs um engenhoso procedimento de intervenção, que consiste, basicamente, em formular- 
se a questão de interesse com uma dada probabilidade " $p$ " menor que a unidade. Trata-se, na verdade, de oferecer ao entrevistado a possibilidade de responder a uma de duas questőes formuladas, sem que o entrevistador tenha conhecimento de qual das questões está sendo contestada.

Em essência, a utilização deste artificio possibilita que questões "sensíveis" sejam respondidas sem constrangimentos, posto que a privacidade do entrevistado com respeito à característica "sensível" é mantida. Tal procedimento foi denominado "Randomized Response Technique"/RRT ou, em português, "Técnica de Resposta ao Azar"/TRA. Assumindo-se, então, que o interesse da pesquisa resida em estimar a proporção de pessoas da população que apresenta uma determinada característica estigmatizante uso de drogas, homossexualismo, provocação de um aborto, etc. - , tal como no procedimento convencional extrai-se da populaçăo uma amostra representativa de " $n$ " pessoas, tomando-se as devidas precauçőes para garantir que cada pessoa seja entrevistada. Para garantir que a pessoa coopere, isto é, que responda verdadeiramente, Warner idealizou a seguinte alternativa: para realizar-se a pesquisa, cada entrevistador é provido de um pião que assinala a letra " $A$ " com probabilidade " $p$ " e a letra " $B$ " com probabilidade (1-p), orientando-se os entrevistados para identificarem-se com a letra " $A$ " se for portador do atributo de interesse e, em caso contrário, com a letra " $B$ "; em cada entrevista, pede-se ao entrevistado que, sem ser observado pelo entrevistador, rode o piăo e declare se este assinala ou não o grupo ao qual pertence. $O$ entrevistado não declara ao entrevistador a letra indicada pelo pião, só contesta "sim" ou "não".

Com respeito à fixaçăo do valor de "p", deve-se ressaltar que esta assume importância fundamental no emprego da TRA. Como aquela probabilidade associa-se à questão de interesse, é conveniente que assuma um valor tão próximo de 1 quanto possível; todavia, ao entrevistado pede-se menos quanto maior for sua chance de selecionar a letra " $B$ ", isto é, quanto menor for o valor de " $p$ ". Ora, é bastante intuitivo que para $p=0.5,0$ entrevistado năo fornece nenhuma informaçăo; para $p=1$, todo o procedimento reduz-se a requerer do entrevistado que responda reservadamente se pertence ou não ao grupo " $A$ " 
e para " $p$ " assumindo um valor entre 0.5 e 10 entrevistado fornece informação útil. Nesse sentido, " $p$ " pode ser pensado como descrevendo a natureza da cooperação entre pesquisador e entrevistado (WARNER, 1965).

Por outra parte, a questão do tamanho amostral requerido para um dado nivel de precisão, também depende do paråmetro " $p$ ". Com efeito, quanto mais próximo do valor unitário estiver " $\mathrm{p}$ ", menor será o tamanho amostral requerido. Exemplificando, tomandose $W$ igual a 0.5 e " $p$ " igual a 0.75 , a variância de $W$ resume-se a $1 / \mathrm{n}$; isto implica que para garantir um desvio padrão de 0.05 o tamanho amostral deve girar ao redor de 400 . Em contrapartida, se "p" assume o valor máximo - o que equivale a utilizar-se o método convencional de estimaçăo -, a referida variáncia iguala-se a 1/4n, ou seja, o tamanho amostral requerido deve ser de apenas 100 para garantir o mesmo desvio padrão (WARNER, 1965).

Como na efetivação do emprego da técnica dever-se-á adotar um valor para $p$ obrigatóriamente menor que 1, o tamanho amostral será, nos desenhos amostrais convencionais, necessariamente mais elevado neste procedimento que no da abordagem direta.

Afortunadamente, entretanto, é possível recorrer-se aos planos simplificados de amostragem, cujo uso encontra-se em plena expansão na área da Saúde Pública e da Epidemiologia. Um exemplo típico é o idealizado para avaliação da cobertura vacinal que consite, grosso modo, em sortear-se 30 unidades primárias - quadras ou quarteirões - e nestas, efetivar a entrevista em 10 domicilios, a partir de um início casual. Este método de sorteio produz resultados que não se distanciam significativamente do método equiprobabilístico, além de ser de simples implementaçào e de custo bastante reduzido. (ALVES CARDOSO, 1990).

Mesmo na perspectiva de se necessitar de um tamanho amostral elevado, o enorme interesse pela TRA, por parte dos mais diversos estudiosos direcionou-os a buscarem alternativas que viessem aprimorá-la. Assim, do modelo original, surgiram inúmeras 
alternativas de jogo. (SILVA, 1992). Ao nosso ver, a contribuição mais relevante para o aperfeiçoamento do modelo original baseia-se em uma idéia lançada por Simnons, apresentada em HORVITZ et alii (1967) e posteriormente adaptada por GREENBERG et alii (1969). Partindo-se da premissa de que, dando-se a oportunidade do respondente contestar uma de duas questões - tal como idealizado por Warner -, sendo uma completamente inócua e não relacionada com o atributo estigmatizante, o entrevistado ver-se-ia mais encorajado a responder verdadeiramente, Simnons propôs que o atributo $B$, da técnica original, fosse substituido por um atributo $C$ neutro. Por exemplo, as seguintes perguntas poderiam ser formuladas:

1. Você já provocou algum aborto?

2. Você nasceu no mês de abril?

Então, utilizando-se a proposta de Warner, ao formular-se a primeira pergunta com probabilidade $p$ e a segunda com probabilidade ( 1 - $p)$, a seguinte equação deve ser resolvida:

$$
K=W p+Z(1-p)
$$

Onde $k$ representa á proporção de respotas afirmativas; $Z$ a proporção de pessoas da populaçăo que nasceram no mês de abril e; $W$ a proporção de pessoas com história de aborto. As Estatísticas de Registro Civil ou dados de outras pesquisas, permitem o conhécimento da proporçăo da populaçăo nascida no mês de abril, ou seja, é conhecida a priori.

Enfim, evidencia-se, claramente, o valor potencial da TRA.

\section{NIVEIS E TENDÊNCIAS DO ABORTO PROVOCADO NA AMÉRICA LATINA}

A comissão organizadora do Encontro de Investigadores sobre aborto induzido na América Latina e Caribe, ocorrido em Bogotá, entre 15 a 18 de novembro de 1994, após a 
análise dos papers expostos, concluiu que estes, via de regra, avaliam a ocorrência do evento em pauta em função da idade, escolaridade, atividade econômica, número de filhos, prática contraceptiva, estrato social e religiosidade da mulher. Constatou-se que a intensidade e direção das associações varia de país a país, bem como dentro de um mesmo pais, segundo a história anticonceptiva e a cultura regional.

Não obstante, pode-se identificar dois cenários "padrăo". Um, dos países que encontraram dificuldades em implementar um programa de planejamento familiar, ou que o implementaram tardiamente. $O$ outro, relativo aos paises com ampla disponibilidade de anticoncepção e onde os programas de planejamento familiar se iniciaram precocemente.

No primeiro caso, as mulheres que recorrem ao aborto têm mais de 30 anos de idade, são pobres, pouco escolarizadas e com descendência numerosa. As razões expressadas com mais frequência para justificar a recorrência àquela prática são: dificuldades econômicas, o fato de ser solteira e um número elevado de filhos. A maioria dessas mulheres conheçem todos os métodos contraceptivos mas fazem pouco uso deles. Anota-se altas porcentagens de usuárias de métodos tradicionais pouco eficazes, tanto quanto um baixo tempo de uso. A pobreza e/ou dificuldades econômicas deixam de ter importância na opção pelo aborto e começam a despontar as razões como o éxito, o alcance de um projeto de vida e outras valoraçőes de realização pessoal distintas da maternidade.

No segundo caso, as mulheres que provocam abortos ou são bastante jovens ou estăo em vias de terminar seus ciclos reprodutivos, possuem escolaridade das mais elevadas, encontram-se no limite superior da escala sócio-económica e participam maiormente da força de trabalho. O número de filhos năo é um diferenciador e tampouco 0 estado conjugal. Tais mulheres conhecem e costumam recorrer a métodos eficazes de controle natal e engravidam por ocasiăo do descanso ou interrupção do método. 
Nossa experiência, suportada pela realização de entrevistas domiciliares em dois contextos paulistas, a Cidade de São Paulo e o sub-distrito de Vila Madalena, ambos com uma realidade mais próxima ao desse segundo padrão descrito, evidencia um terceiro perfil para as usuárias de aborto. Qual seja: aceitar-se com flexibilidade a prática - razões econômicas, solteirismo, familia completa ou mesmo por qualquer motivo de ordem pessoal -, é o fator de maior peso na efetivação da mesma. O segundo fator a diferenciar substancialmente o comportamento do aborto provocado é o estado conjugal. As mulheres solteiras recorrem à prática em maior escala e $o$ fazem quase que independentemente de qualquer outro fator. Mesmo quando manifestam-se rigidamente contra tal prática - só a aceitam nos casos previstos por lei ou não a aceitam em hipótese alguma -, recorrem a ela na ânsia de por fim a uma gravidez inoportuna e/ou indesejada. As mulheres casadas, em contrapartida, quando são contra a prática, não recorrem ao aborto. Quando aceitam, recorrem à mesma visando ou espaçar um nascimento do outro ou manter a familia dentro dos limites desejados. Nesta situação, a maioria das mulheres acaba buscando a solução definitiva, ou seja, a esterelização.

A escolaridade ocupa o terceiro lugar em importância na explicação da variabilidade de ocorrência do aborto. Contudo, só afeta o comportamento das mulheres unidas, de sorte que uma alta escolaridade favorece a ocorrência daquele. A diferença entre o número de nascidos vivos e o número de filhos considerado ideal explica apenas modestamente aquela variabilidade, incrementando, quando positiva, a ocorrência entre as mulheres unidas e com alta escolaridade $e$, inversamente, incrementando a ocorrência entre as não casadas, independentemente do nivel de escolaridade que possuam.

Apesar dos desencontros apontados pelos perfis esboçados acima, eles permitem responder satisfatoriamente ao menos duas questões chaves: Qual o perfil da mulher que recorre ao aborto? Por que elas recorrem a tal prática? Ora, recorrem ao aborto tanto as mulheres que se encontram no início como as que se encontram no final de suas vidas reprodutivas, sobretudo as primeiras. $O$ fazem, seguramente, por conta da 
precariedade de alternativas contraceptivas que se adequem àqueles momentos especiais da vida reprodutiva - as altas porcentagens de esterelização feminina endossam esse argumento.

Dificil, certamente, é contestar com a mesma propriedade a pergunta: Quantas mulheres provocam um aborto, num determinado período de tempo, numa dada localidade?

Realizando um balanço na literatura disponivel nos anais do já mencionado Encontro da Colombia, encontram-se apenas dois trabalhos que lograram êxito nessa tarefa: o que relata nossa experiência com o emprego da TRA (SILVA, 1994) e o elaborado a partir da pesquisa levada a cabo pelo Instituto Alan Guttmacher (SINGH E WULF, 1994). Ambos apontam para o Brasil uma ocorrência de aproximadamente 1,5 milhões de abortos/ano.

\section{CONSIDERAÇÕES FINAIS}

Apesar da precariedade da informaçăo básica - aborto ilegal -pode-se apreender que as mulheres mais expostas aos riscos de sequelas subsequentes à prática do aborto clandestino, inclusive com considerável risco de morrer, são as que se encontram no início de suas vidas reprodutivas, seguidas pelas que se encontram no final desse ciclo. Assim sendo, faz-se necessário que tanto as autoridades como os profissionais da área da Saúde, dediquem atenção especial a tais mulheres, quer implementando campanhas educativas, quer facilitando-se o acesso a contraceptivos eficazes ou ainda $e$, fundamentalmente, investindo-se em pesquisas que visem à produçăo de métodos inócuos e adequados àquelas faixas etárias.

Por outro lado, para proceder-se a uma adequada avaliação das relações que permeiam o binômio aborto provocado e saúde reprodutiva, ainda há muito a percorrer na direçăo de contar-se com resultados que sejam incontestáveis. Um passo à frente nessa 
trilha, acreditamos, é definir-se inequivocamente e, universalmente, cada uma das taxas de aborto provocado. Outro, é lançar-se mão de pesquisas domiciliares, metodologicamente impecáveis. Para tanto, recomenda-se a extraçăo de uma amostra aleatória de domicilios e o emprego da TRA. Um desenho amostral altamente recomendável, tanto pelo seu reduzido custo quanto pela precisăo dos resultados que produz, é o elaborado para avaliaçăo de cobertura vacinal - este enquadra-se nos chamados métodos amostrais rápidos ou simplificados.

Quanto à TRA recomenda-se o uso da modalidade que contempla a formulação de uma questão inócua, descrita no item $\mathrm{V}$ ou, para os menos afeitos às probabilidades, a modalidade de resposta sigilosa nos moldes em que se computam os votos em pleitos eleitorais - uma descrição mais detalhada desta modalidade, pode ser encontrada em SILVA (1990) ou em ZAMUDIO et alii (1994), que tiveram a oportunidade de empregá-la numa pesquisa efetuada na Colombia.

Uma legislação tolerante na matéria, certamente, acarretaria uma substacial redução dos riscos subsequentes à provocaçăo do aborto, bem como dispensaria os dribles metodológicos da TRA. Ou seja, as recomendações acima, excetuando-se a referente às taxas, são válidas apenas para as localidades onde, desafortunadamente, faz-se necessário recorrer à prática clandestina. O politicamente correto seria, portanto, conviver-se com uma legislação mais tolerante, sem deixar de proteger rigorosamente a mulher, a criança e a maternidade. Neste caminho năo há perdas: ao contrário, há apenas ganhos sob todos os pontos de vista.

\section{REFERÊNCIAS BIBLIOGRAFIAS}

ALVES CARDOSO, M.R. Comparação entre trés métodos de amostragem que visam à estimação da cobertura vacinal. Săo Paulo, 1990. [Dissertaçăo de Mestrado Faculdade de Saúde Pública da USP].

BERQUO, E.S. \& MERRICK, T.W. The determinants of Brazil's recent rapid decline in fertility. Washington, D.C. Committee on Population and Demography, National Academy Press., 1983. 
BERQUO, E.S. et al. São Paulo e sua fecundidade: um estudo das variáveis intermediárias e dos diferenciais sócio-econômicos da fecundidade. Fundação SEADE, São Paulo, 1985.

BOONGARTS, S. The fertility inhibiting effects of the intermediate fertility variables. London, april, 1980. [Paper prepared for the IUSSP and WFS Seminar on the Maternity Histories].

$\mathrm{CHI}$, I.C. et al. The randomized response techniques as used in the Taiwan outcome of pregnancy study. Stud. Family Plan., 3:265-9, 1972.

CHOW, L.P. et al. Feasibility of the randomized response technique in rural Ethiopia. Am. J. Public Health, 69:273-6, 1979.

CRAFT, I. et al. Consequences of induced abortion. Lancet, 1:437, 1979

DAVID, H. P. Abortion policies. In: HODGSON, J.E. Abortion and Sterelization: medical and social aspects. New York, Academic Press, 1980. p.1-40.

DAVID, H.P. Abortion research: international experience. Lexington, Lexington Books, 1974.

DAVID, H.P. \& FRIEDMAN, H.L. Psychosocial research in abortion: a transnational perspective. In: OSOFSKY, J.D. et al eds. The Abortion Experience, p.310-37.

DAVID, H.P. e PICK DE WELLS, S. El aborto en las Américas. In: Organización Panamericana de la Salud. Salud reproductiva en las Américas. Washington, D.C., 1994. p. 377-9.

FUNDAÇÃO SEADE A fecundidade da mulher paulista. São Paulo, 1994. Coleção Informe Demográfico, (n.25).

GASLONDE, S. Analisis preliminar de algunos datos sobre abortos provenientes de encuestas en América Latina. Santiago do Chile, CELADE, 1973. (CELADE. Série $\left.A, n^{\circ} 118\right)$.

GREENBERG, B.G. et al. The unrelated question randomized response model: theorical framework. J. Am. Stat. Ass., 64: 520-39, 1969.

HENSHAW, S.K. et al. Abortion services in the United States, 1979 and 1980. Family Plan. Perspec., 14:5-15, 1982.

HOGUE, C.J. et al. The effects of induced abortion on subsequent reproduction. Epidemiol. Rev., 4:66-94, 1982. 
HOLLERBACH, P. E. Recent trends in fertility, abortion and contraception in Cuba. Int. Family Plan. Perspec. 6: 97-106, 1980.

HORVITZ, D.G.; SHAH, B.V.; SIMMONS, W.R. The unrelated question randomized response model. Proc. Soc. Stat. Sec. Am. Stat. Ass., 1967.

ISAACS, S. L. \& SANSHUEGA, H. Induced abortion in Latin America: the legal perspective. In: Pan American Health Organization and Transational Family Research Institute. Epidemiology of abortion and pratics of fertility regulation in Latin America: selected reports. Washington D.C., 1975. Scientific Publication, 306, p:39-52.

KROTKI, J.K. \& MC.DANIEL, S.A. La technique de réponse rendue aléatoire: quelques résultats d'une étude Ó Edmonton, Canada. Popul. et Famille, 41:91-119, 1977.

MOORE-CAVAR, E.C. International inventory of information on induced abortion. New York, International Institute for the Study of Human Reproduction, Columbia University, 1974.

MOORE-CAVAR, E.C.; POTTER, R.G.; FORD, R. Repeat abortion. Demography, 13: 6579, 1976.

ORGANIZAÇÃO MUNDIAL DA SAÚDE. Aborto espontâneo e provocado. Genebra, 1970. Série Informe Técnico, $n^{\circ} 461$.

ORGANIZAÇÃO MUNDIAL DA SAÚDE. Aborto provocado. Genebra, 1978. Série Informe Técnico, $n^{\circ} 623$.

ORGANIZAÇÃO MUNDIAL DA SAÚDE. Task Force on Sequelae of Abortion. Gestation, birthweight and spontaneous abortion in pregnancy after induced abortion. Lancet, 1, n० 8108: january, 1979.

PACK, A. \& MARCUS, H. Psychiatric sequelae of the therapeutic interruption of pregnancy. J. Nerv.Mental Dis., 143:417-25, 1966.

REQUENA, M. Estudio sobre la planificación de la familia en la Comuna de Quinta Normal de Santiago de Chile. Milbank Mem. Fund Q., 43:66-94, 1965.

RIDER, R.V.; HARPER, A.P.; CHOW, L.P., CHI, I.C. A comparison of four methods for determining prevalence of induced abortion - Taiwan, 1970-1971. Am. J. Epidemiol., 103:37-50, 1976.

SANTEE, B. A prospective abortion study in Santiago, Chile. Organización Panamericana de la Salud. Epidemiology of abortion and practices of fertility regulation in Latin America. Washington, 1975. p:30-8 Publicación Científica, nº 306. 
SILVA, R.S. Técnica de resposta ao azar (TRA): uma proposta alternativa. In: $7^{\circ}$ Anais Encontro Nacional de Estudos Populacionais. Caxambú, 1990. Anais, Minas Gerais, p:517-37.

SILVA, R.S. Aborto provocado: sua incidência e caracteristicas: um estudo com mulheres em idade fértil, residentes no sub-distrito de Vila Madalena. São Paulo, 1992.[Tese de Doutoramento - Faculdade de Saúde Pública da USP].

SILVA, R.S. Incidência e características do aborto induzdo em São Paulo. In: Encuentro de Investigadores sobre Aborto Inducido en América Latina y el Caribe.Santafé de Bogotá. Anais. Universidad Externado de Colombia, 1994. vol.Aspectos Metodológicos.

SINGH, S. \& WULF, D. Estimating abortion levels in Brazil, Colombia and Perú, using hospital admissions and fertility survey data. Int. Family Plan. Perspec., 17:8-13, 1991.

SINGH, S. \& WULF, D. Niveles estimados de aborto inducido en seis paises latinoamericanos. In: Encuentro de Investigadores sobre Aborto Inducido en América Latina y el Caribe. Anais. Santafé de Bogotá, Universidad Externado de Colombia, 1994. vol. Incidencia.

TEZCAN, S. \& OMRAN, A.R. Prevalence and reporting of induced abortion in Turkey: two survey techniques. Stud. Familly Plan., 12, 67:262-71, 1981.

TIETZE, C. \& LEWIT, S. Joint program for the study of abortion (IPSA): early medical complications of legal abortion. Stud. Family Plan., 3 (6):97-122, 1972.

TIETZE et al. Mortality associated with yhe control of fertilit. Family Plan. Perspec., 8:614, 1976.

TIETZE, C. \& LEWIT, S. Life risks associated with methods of fertility regulation. Int. J. Gynecol. Obstet., 16:456-9,1979.

TIETZE, C. Induced abortion: 1980. New York, Population Council, 1980.

WARNER, S.L. Randomized response: a survey technique for eliminating evasive answer bias. J. Am. Stat. Ass. 60: 63-9, 1965.

WOLF, S.R. Therapeutic abortion, a lyasar phychiatric's perspective. In: NEWMAN, S.H. Abortion obtained and derrid. Ed. loc., cit, 1971. 
ZAMUDIO, L., RUBIANO, N.; WATENBERG, L. Representatividad, confiabilidad y significación: problemas práticos de la investigación sobre aborto inducido. In: Encuentro de Investigadores sobre Aborto Inducido en América Latina y el Caribe. Santafé de Bogotá, Universidad Externado de Colombia, 1994. vol. Aspectos Metodológicos.

\begin{abstract}
Summary: Trusworthy statistics on provoked abortion form countries where this practice is generalized allow for an adequate evaluation of the impact of abortion on Reprodutive Health. Paradoxically it is in these very countries that the less severe damage to Reproductive Health are observed. At the same time, even based on little or totally not trustworthy data the cost of clandestine practice is very high: its sequels are frequent and often lead to death. Evaluating how high these costs are, however, is a rather hard task that depending on the desired focus may even not be feasible. The best solution for such dilemma would be, according to the literature, the legalization of abortion. In this case the analysis of the duet Abortion/Health besides automatically reducing the costs on the clandestine practice would allow for the removal of the remaining costs. Nevertheless, while one has to live under a restrictive legislation the most sensible solution is optimizing the quality of analysis of that duet. One can in this sense adopt a statistical technique that removes the biggest obstacle to the determination of the dynamics of illegal abortion i.e. the under register/and/or under register of abortion frequency the RRT. One can also design population studies from a simplified sampling plan for they are very rare in comparison to hospital based analysis.

Key words: induced abortion; reprodutive health; simplified sampling
\end{abstract}

